\title{
Erratum to: Spatial-temporal characteristics of surface water quality in the Taihu Basin, China
}

\author{
Guangju Zhao $\cdot$ Junfeng Gao $\cdot$ Peng Tian $\cdot$ \\ Kun Tian · Guangheng Ni
}

Published online: 15 June 2011

(C) Springer-Verlag 2011

\section{Erratum to: Environ Earth Sci \\ DOI 10.1007/s12665-011-0902-6}

Unfortunately the authors' affiliations were incorrect.

The online version of the original article can be found under doi:10.1007/s12665-011-0902-6.

\section{G. Zhao $(\bowtie)$}

Institute of Soil and Water Conservation, Northwest A \& F University, Yangling 712100, People's Republic of China

e-mail: guangjuzhao@yahoo.com

\section{G. Zhao}

Institute of Soil and Water Conservation, Chinese Academy of Sciences and Ministry of Water Resources, Yangling 712100,

Shaanxi Province, People's Republic of China

\section{G. Zhao}

Department of Hydrology and Water Resources Management, Institute of Natural Resources Conservation,

Kiel University, Olshausenstr. 75, 24118 Kiel, Germany

\section{J. Gao}

Nanjing Institute of Geography and Limnology,

Chinese Academy of Sciences, Nanjing 210008,

People's Republic of China

\section{P. Tian}

College of Water Resources and Architectural Engineering, Northwest A \& F University, Yangling 712100,

People's Republic of China

\section{K. Tian · G. Ni}

State Key Laboratory of Hydro-Science and Engineering, Department of Hydraulic Engineering, Tsinghua University, Beijing 100084, People's Republic of China
The correct information is given below:

G. Zhao $(\bowtie)$

Institute of Soil and Water Conservation,

Northwest A \& F University, Yangling 712100,

People's Republic of China

e-mail: guangjuzhao@yahoo.com

\section{G. Zhao}

Institute of Soil and Water Conservation,

Chinese Academy of Sciences and Ministry

of Water Resources, Yangling 712100, Shaanxi Province, People's Republic of China

\section{G. Zhao}

Department of Hydrology and Water Resources

Management, Institute of Natural Resources Conservation, Kiel University, Olshausenstr. 75, 24118 Kiel, Germany

\section{J. Gao}

Nanjing Institute of Geography and Limnology,

Chinese Academy of Sciences, Nanjing 210008,

People's of Republic of China

P. Tian

College of Water Resources and Architectural Engineering, Northwest A \& F University, Yangling 712100,

People's of Republic of China

K. Tian · G. Ni

State Key Laboratory of Hydro-Science and Engineering, Department of Hydraulic Engineering,

Tsinghua University, Beijing 100084,

People's Republic of China. 